\title{
磁気軸受ホイールを搭載した人工衛星の 姿勢運動の安定性と制御
}

\author{
井上 正夫*・二宮 敬 虔**
}

\author{
Stability and Control of Attitude Motion of a \\ Satellite Equipped with a Magnetic Wheel
}

Masao Inoue* and Keiken NinomiYA**

\begin{abstract}
Introducing magnetic suspension to the momentum wheel of an artificial satellite is expected to enhance the reliability and the maneuvability of the satellite. However, as the stiffness of the magnetic bearing is rather small, the attitude motion of the satellite may be coupled with the wheel precession to become unstable. Although the attitude motion may be able to be stabilized at the cost of reducing the stability of the wheel precession when the tilting angles of the wheel are controlled actively, it has been difficult to get sufficient stability margin both in the attitude motion of the satellite and in the precessional motion of the wheel without attitude sensors. This paper proposes the new strategy to offer large damping factor both to the satellite motion and to the wheel precession without attitude sensors. That is achieved by introducing an observer which estimates the attitude-rate of the satellite. It is provided that the observer-based compensation is equivalent to the low-pass-filtering whose cut-off frequencies are as low as those of the attitude motion of the satellite. Some numerical examples displayed that the system has good performances.
\end{abstract}

Key Words: magnetic suspension, attitude control, observer, gyroscopic dynamics

\section{1.はじめに}

モーメンタムホイールは人工衛星の姿勢を安定化す

* 三菱電機 (株) 中央研究所 尼崎市塚口本町 8-1-1

** 宇宙科学研究所 相模原市由野台 3-1-1

* Central Research Laboratory, Mitsubishi Electric Corporation, Amagasaki

** The Institute of Space and Astronautical

Science, Sagamihara

(Received April 6, 1989)

(Revised June 23, 1989)
る有効な手段として多くのシステムに利用されている が，ホイール軸受の寿命が人工衛星全体の信頼性に大 きい影響を及ぼすととになるので, 軸受の信頼性を確 保することが重要となる。しかし，従来用いられてい る玉軸受の寿命は経験的にしか評価できず，不確定要 因が多いために均質な品質の製品を得るととが難しい という問題があった．また，長寿命とするためには回 転速度を低くおさえねげならないので，必要な角運動 量を得るために重量の大きいホイールを使わねばなら ないという欠点もある.

非接触で回転体を支持できる磁気軸受をモーメンタ ムホイールの軸受に適用することが, 玉軸受のとのよ うな困難を解決するすのとして検討されている1 . 磁 気軸受としては, 永久磁石を用いた部分的な受動安定 化方式が搭載上有利と考えられていたが，ホイールと 人工衛星の力学的な連成によって姿勢運動が不安定に なることが示され2), 能動的な磁気軸受を用いてホイ 一ル回転軸の傾きに関する運動にクロスフィードバッ クを加えることによって, 人工衛星の姿勢運動を安定 化する方式が提案された ${ }^{5 /, 6)}$.

一方, 磁気軸受単独では, 高速回転時のプリセッシ ヨン運動を安定化するためにクロスフィードバックを 加えるてとが報告されている31,4). ところが，乙のク ロスフィードバックは前記の人工衛星の姿勢運動を安 定化するためのクロスフィードバックとはまったく正 反対の効果があるため，両者を同時に安定化すること が困難であった。

\section{2. 磁気軸受制御の人工衛星の 姿勢運動への寄与}

Fig. 1 のような人工衛星において, 磁気軸受支持 されたホイールがそのノミナルな回転軸が $Y$ 軸と平行 


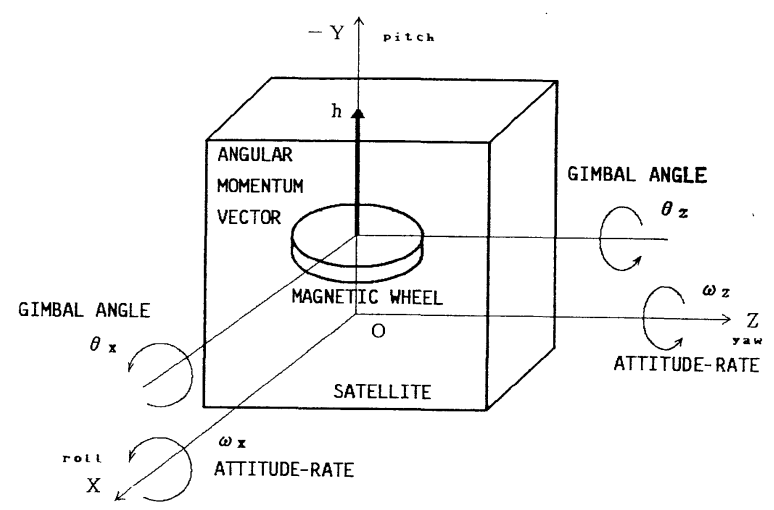

Fig. 1 Mathematical model of a satellite equipped with a magnetic wheel

に搭載されて一定速度で回転しているとする. このと き, 人工衛星の $X$ 軸, $Z$ 軸まわりの微小姿勢角速度を $\omega_{x}, \omega_{z}$, ホイールの半径方向軸まわりの微小回転角度 (以後これをジンバル角度と呼ぶ）を $\theta_{x}, \theta_{z}$ とすれ ば，乙の系の運動は方程式 (1)，（2)で近似的に表現 できる。

$$
\begin{aligned}
& I_{x} \dot{\omega}_{x}=-u_{x} \\
& I_{z} \dot{\omega}_{z}=-u_{z} \\
& J\left(\dot{\omega}_{x}+\ddot{\theta}_{x}\right)+h\left(\omega_{z}+\dot{\theta}_{z}\right)=u_{x} \\
& J\left(\dot{\omega}_{z}+\ddot{\theta}_{z}\right)-h\left(\omega_{x}+\dot{\theta}_{x}\right)=u_{z}
\end{aligned}
$$

ここで, $I_{x}, I_{z}$ はそれぞれ $X$ 軸, $Z$ 軸まわりの人工衛 星の慣性モーメント，Jはホイールの回転軸に垂直な 軸まわりの慣性モーメント, $h$ はホイールの角運動 量, $u_{x}, u_{z}$ は $X$ 軸, $Z$ 軸まわりの磁気軸受制御トル クである.

ホイール単独としてのジャイロ運動にはニューテー ション (章動) とプリセッション (歳差) の二つのモ ードがあるが3), ニューテーションは固有周波数がき わめて高いので近似的にてれを無視しても人工衛星の 姿勢運動への影響は小さいと考えられる. これはホイ ールの慣性 $J$ を無視することに相当し，（2)式はさら に(3)式のように近似される.

$$
\begin{aligned}
& h\left(\omega_{z}+\dot{\theta}_{z}\right)=u_{x} \\
& -h\left(\omega_{x}+\dot{\theta}_{x}\right)=u_{z}
\end{aligned}
$$

磁気軸受制御トルク $u_{x}, u_{z}$ は (4) 式のようにジンバ ル角度 $\theta_{x}, \theta_{z}$ のフィードバックで与えられるとする.

$$
\begin{aligned}
& u_{x}=-k_{d} \theta_{x}+k_{c} \theta_{z} \\
& u_{z}=-k_{d} \theta_{z}-k_{c} \theta_{x}
\end{aligned}
$$

ここで， $k_{d}$ は軸受に剛性を与えるための直接フィー ドバックゲイン, $k_{c}$ はプリセッションを補償するク ロスフィードバックゲインである. 実際にはさらにニ ューテーションを安定化するための $\dot{\theta}_{x}, \dot{\theta}_{z}$ に関する
レートフィードバックが必要だが，乙こではホ イールのニューテーションが安定であるてとを 前提とした解析を行っているのでてれを近似的 に無視した.

さて，解析を簡単にするため $I \equiv I_{x}=I_{z}$ を仮 定し, 複素変数 $\Omega \equiv \omega_{x}+i \omega_{z}, \Theta \equiv \theta_{x}+i \theta_{z}, U \equiv$ $u_{x}+i u_{z}, K \equiv k_{d}+i k_{c}$ を導入すると, (1),

(3), (4) 式は (5)〜 (7) 式で表現される.

$$
\begin{aligned}
& I \dot{\Omega}=-U \\
& -i h(\Omega+\dot{\Theta})=U \\
& U=-K \Theta
\end{aligned}
$$

人工衛星の姿勢運動とホイールのプリセッショ ンの安定は ( 5$) \sim(7)$ 式の固有值によって評価 できる. 固有值を入とすると特性方程式は (8) 式となり，その根は近似的に(9)式と解ける.

$$
\begin{aligned}
& \lambda^{2}+i \frac{K}{h} \lambda+\frac{K}{I}=0 \\
& \lambda_{s} \fallingdotseq \frac{-k_{c} h^{3}}{I^{2}\left(k_{c}^{2}+k_{d}^{2}\right)}+i \frac{h}{I} \\
& \lambda_{w} \fallingdotseq \frac{k_{c}}{h}-i \frac{k_{d}}{h}
\end{aligned}
$$

ここで $\lambda_{s}$ は人工衛星の姿勢運動から派生した固有值, $\lambda_{w}$ はホイールのプリセッションから派生した固有值 を表わしている.（9)式の導出では小型の科学衛星の パラメータのオーダーが

$$
\begin{aligned}
& I \sim 10^{2} \mathrm{kgm}^{2} \\
& h \sim 10^{1} \mathrm{Nms} \\
& k_{c}, k_{d} \sim 10^{2} \mathrm{Nm}
\end{aligned}
$$

であるととを考慮して $\sqrt{1+\varepsilon} \fallingdotseq 1+1 / 2 \varepsilon-1 / 8 \varepsilon^{2}, \quad(|\varepsilon|$ 《1）と展開した.

(9)式の実部に注目すると, 人工衛星の姿勢運動が 安定なためには $k_{c}>0$ でなければならないのに対し， ホイールのプリセッションを安定化するためには $k_{c}$ く0でなければならない. したがって，(4)，（7)式 のような単純な制御則では両者を同時に安定化するこ とが困難である.

ただし $\operatorname{Re}\left(\lambda_{s}\right)$ のオーダは $10^{-3}$ と非常に小さく, また実際には $k_{c}=0$ であっても (3)，(6)式で無視し たホイール慣性 $J$ のおかげで $\lambda_{w}$ はやや安定である. そこで， $k_{c}$ をわずかに正に選ぶてとによって，人工 衛星の運動を安定化するという手法が提案されてい $る^{2), 5,6)}$. しかし, このことはホイールのプリセッシ ョンの減衰を損ない, また $(9 \mathrm{a})$ 式が示すように, $k_{c}$ の $\operatorname{Re}\left(\lambda_{s}\right)$ への寄与がそもそも小さいので, 姿勢運動 の減衰を十分大きくすることはできず，結局どちらの 運動む安定の余裕がきわめてそしくなるという問題が 
あった。

\section{3. 姿勢角速度センサを用いた磁気軸受の制御}

さて，実際の人工衛星においては，光学的あるいは 慣性的なセンサを用いて姿勢角度誤差や姿勢角速度䛊 差を検出し，それを姿勢制御アクチュエータへフィー ドバックすることによって能動的な姿勢制御を行うの が一般である，その場合には人工衛星の姿勢運動の減 衰は十分大きいので， $k_{c}<0$ であっても安定性は保た れる. しかし，時として姿勢センサの情報が得られな くなった場合には前節で示したように姿勢運動が不安 定になる状況が生じうるわけである.

ジャイロなどの姿勢角速度センサが使用できると すれば，制御系は Fig. 2 のように構成するととがで き, 磁気軸受の制御トルクはラプラス変換した形で (11)または (12)式と与えられる7).

$$
\begin{aligned}
& {\left[\begin{array}{l}
u_{x}(s) \\
u_{z}(s)
\end{array}\right]=-\left[\begin{array}{rr}
k_{d}-k_{c} \\
k_{c} & k_{d}
\end{array}\right]\left[\begin{array}{l}
\theta_{x}(s)+k_{r} \frac{\omega_{z}(s)}{s+\omega_{0}} \\
\theta_{z}(s)-k_{r} \frac{\omega_{x}(s)}{s+\omega_{0}}
\end{array}\right]} \\
& U(s)=-K\left[\Theta(s)-i k_{r} \frac{\Omega(s)}{s+\omega_{0}}\right]
\end{aligned}
$$

ここで， $s$ はラプラスの演算子， $k_{r}$ は姿勢角速度の フィードバックゲイン， $\omega_{0}$ は姿勢角速度 $\Omega$ の積分が ドリフトしないように，低周波数領域でのゲインを制 限するための定数である.

(11)，（12）式では通常の状態フィードバックと異な り，姿勢運動を減衰させるために姿勢角速度の近似的 な積分量を用いているが，その理由は以下のとおりで ある。

（1），（3）式よりuを消去すると,

$$
\begin{aligned}
& I_{x} \dot{\omega}_{x}+h \omega_{z}=-h \dot{\theta}_{z} \\
& I_{z} \dot{\omega}_{z}-h \omega_{x}=h \dot{\theta}_{x}
\end{aligned}
$$

を得る. (13)式左辺は角運動量をもつ剛体に対する近 似的なオイラーの運動方程式であるから，右辺は人工 衛星に加わるトルクの近似量と考えるととができる. 人工衛星の姿勢運動に減衰を加えるためには，姿勢角 速度に比例したトルクをフィードバックする必要があ るので，その制御ゲインを $K_{r}$ とすれば制御則は $h \dot{\theta}=$ $\pm K_{r} \omega$ ，すなわちジンバル角度への指令としては姿勢 角速度の積分量が必要になる。

$\omega_{0}$ が十分小さいと仮定して (5)，（6)，(12)式を連 立すると特性方程式は (14)となり, その近似解は (15) である。

$$
\begin{aligned}
& \lambda^{2}+i \frac{K}{h} \lambda+\frac{K\left(1+i k_{r}\right)}{I}=0 \\
& \lambda_{s} \fallingdotseq-\frac{h k_{r}}{I}+i \frac{h}{I} \\
& \lambda_{w} \fallingdotseq \frac{k_{c}}{h}-i \frac{k_{d}}{h}
\end{aligned}
$$

(15)式を(9)式と比較すれば， $\lambda_{w}$ に変化がないのに 対し， $\lambda_{s}$ の安定は $k_{c}$ によってではなく， $k_{r}$ によっ て支配されるようになり，その絶対值む大きくできる ことがわかる．したがって，プリセッションを安定化 するために $k_{c}<0$ としても人工衛星の姿勢運動が不安 定になることは避けられる。

ところで，磁気軸受で支持されたホイールは原理的 に2 自由度ジャイロと同一構成であるから，制御トル クを発生させるアクチュエータとしてだけでなく，角 速度センサとしての使用も可能である. ワイスバーク $ら^{8)}$ は磁気軸受制御トルクを制御電流から推定するこ とによって人工衛星の姿勢角速度を計測する試みにつ いて検討したが，ここでは姿勢運動を不安定にしない 磁気軸受制御回路を得るために姿勢角速度の推定量を 利用することを考える.

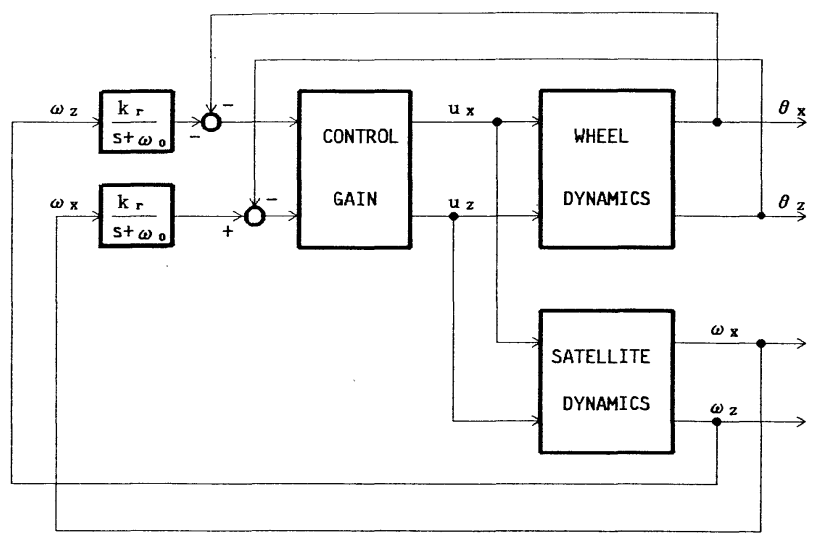

Fig. 2 Block diagram of the control system (with attitude-rate sensors)

\section{4. オブザーバを用いた姿勢角 速度の推定と制御}

運動方程式 (5)，（6)からわかるよう に，乙の系は人工衛星の姿勢とホイールの ジンバル角度とが制御トルクの作用・反作 用によって互いに連成しているので，衛星 の姿勢角速度は直接測定できなくても可観 測であり，オブザーバなどを用いて推定す ることができる。ここでは磁気軸受制御回 路の形を知りたいので,できるだけ単純な 低次元オブザーバ9)を構成する.

観測量 $y$ をジンバル角度 $\Theta$ のみしして (5)，（6)式を書き直すと(16)式となる 
が，これに対して姿勢角速度 $\Omega$ を推定する低次元オブ ザーバは(17)式である.

$$
\begin{aligned}
& \frac{d}{d t}\left[\begin{array}{l}
\Theta \\
\Omega
\end{array}\right]=\left[\begin{array}{rr}
0 & -1 \\
0 & 0
\end{array}\right]\left[\begin{array}{l}
\Theta \\
\Omega
\end{array}\right]+\left[\begin{array}{c}
i / h \\
-1 / I
\end{array}\right] U \\
& y=\left[\begin{array}{ll}
1 & 0
\end{array}\right]\left[\begin{array}{l}
\Theta \\
\Omega
\end{array}\right] \\
& \frac{d z}{d t}=L z+L^{2} \Theta-\left(\frac{1}{I}+i \frac{L}{h}\right) U \\
& \hat{\Omega}=z+L \Theta
\end{aligned}
$$

ただし，Lはオブザーバのゲイン， $z$ はオブザーバの 状態変数, $\hat{\Omega}$ は姿勢角速度の推定值である.

つぎにてのようにして推定された姿勢角速度を用い て磁気軸受の制御を行う。その制御則は (12) 式の $\Omega(s)$ を $\hat{\Omega}(s)$ で置換した(18)式とする.

$$
U(s)=-K\left[\Theta(s)-i k_{r} \frac{\hat{Q}(s)}{s+\omega_{0}}\right]
$$

系の特性根は (12)式の代わりに(18)式を用いても変化 しないととが保証されている9)ので，(15)式の結果に 変わりはなくオブザーバの特性根 $\lambda_{0}$ が付加されるだ

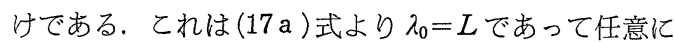
選ぶことができる.

(17)，（18)式で記述された制御系をブロック図で表 わしたのが Fig. 3 である。図で破線で囲まれた部分 が磁気軸受の制御回路を示しているが，てれがどのよ うな特性なのかに興味がある.（17)式をラプラス変換 し，(18)式とから $z(s)$ と $\hat{Q}(s)$ とを消去すれば磁気 軸受制御回路の伝達関数が得られ，(19)式となる.

$$
\frac{U(s)}{\Theta(s)}=-K \frac{s-L-i L k_{r} \frac{s}{s+\omega_{0}}}{s-L+\frac{K k_{r}}{s+\omega_{0}}\left(-\frac{L}{h}+i \frac{1}{I}\right)}
$$

ここで簡単のためオブザーバのゲインLを

$$
\lambda_{0}=L=\frac{h k_{d}}{I k_{c}}
$$

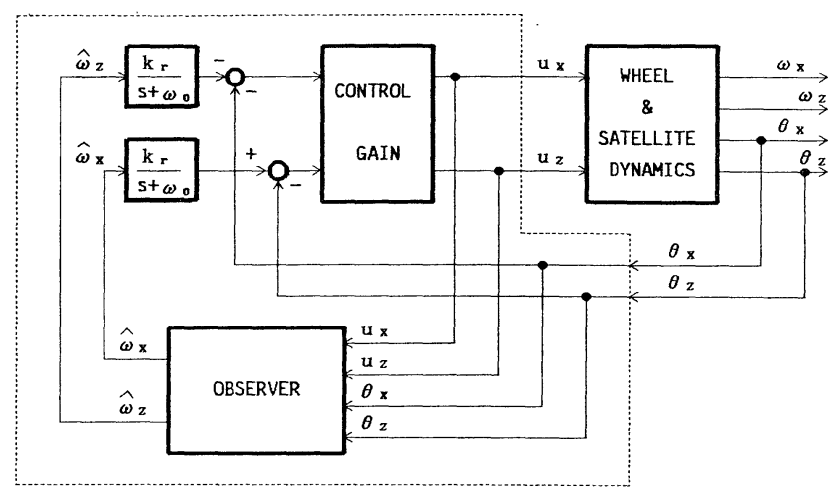

Fig. 3 Block diagram of the control system (with an observer)
と設定すれ゙ば，(19)式は分母が実数となり(21)式のよ うに整理できる.

$$
\frac{U(s)}{\Theta(s)}=-K\left[1-i k_{r} \frac{c s+i d}{s^{2}+a s+b}\right]
$$

ただし，

$$
\begin{aligned}
a & \equiv \omega_{0}-\frac{h k_{d}}{I k_{c}} \\
b & \equiv-\frac{h k_{d}}{I k_{c}} \omega_{0}-k_{r} \frac{k_{d}^{2}+k_{c}^{2}}{I k_{c}} \\
c & \equiv \frac{h k_{d}}{I k_{c}} \\
d & \equiv \frac{k_{d}^{2}+k_{c}^{2}}{I k_{c}}
\end{aligned}
$$

(21) 式右辺第 1 項は人工衛星の姿勢運動を考慮しない 磁気軸受の制御ゲインであり, 第 2 項が人工衛星の姿 勢を安定化するための付加的なフィードバックを表わ している.

一般にオブザーバの推定量をフィードバックする場 合には，系の特性に影響を与えないように，その固有 值実部の絶対值を大きく選んで収束を速やかにする が，過度に大きくすると過渡特性が劣化するので，そ のかねあいで適当な值が選択される．ここで考えてい るシステムでは人工衛星の姿勢運動への影響を避ける ため, $\lambda_{0}$ は実部の絶対值が $\left|\lambda_{s}\right|=h / I$ よりあやや大 きくなるように選ばれるべきである. 通常, $0<-k_{c}$ $<k_{d}$ であるから，(20)式はこの条件を満たしている. さて，(10)式のようなパラメータのオーダで考える と, (22) 式より

$$
\begin{aligned}
& c \sim 10^{-1} \\
& d \sim 10^{\circ}
\end{aligned}
$$

であり，また人工衛星の姿勢運動の固有振動数 $h / I$ は およそ10-1のオーダであるから，(21) 式において cs の効果は $d$ に比べ相対的に小さい. そこでこれを 無視すれば，(18)式との比較で近似的な姿勢角速度推 定量 $\omega_{x}^{*}, \omega_{z}^{*}$ が(24)式で表現される.

$$
\begin{aligned}
& \frac{\omega_{x}^{*}(s)}{s+\omega_{0}} \fallingdotseq \frac{-d}{s^{2}+a s+b} \theta_{z}(s) \\
& \frac{\omega_{z}^{*}(s)}{s+\omega_{0}} \fallingdotseq \frac{d}{s^{2}+a s+b} \theta_{x}(s)
\end{aligned}
$$

これは折点周波数 $\sqrt{b}$ が衛星の姿勢運動の 固有振動数と同程度に低いローパスフィル タである. このことは，人工衛星の姿勢運 動を減衰させるために必要な位相情報はホ イールジンバル角度信号 $\theta_{x}, \theta_{z}$ の低周波 数成分に含まれているということを示して いる.

(24)式によって, 磁気軸受の制御に必要 


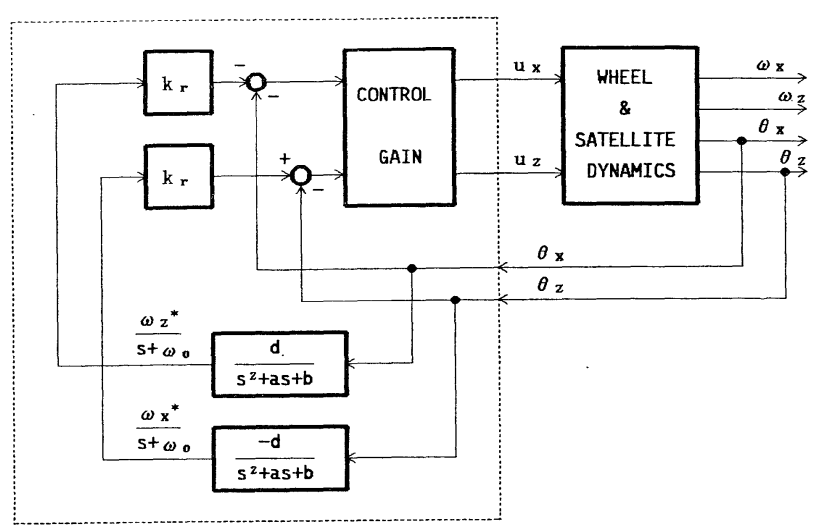

Fig. 4 Block diagram of the control system (with simplified estimators)

な姿勢角速度に関する信号の推定近似が得られたの で，乙れを(18)式の制御則へ適用して Fig. 4 のよう な制御系を構成するととが可能であろうと推測され る.

\section{5. 数值例およびシミュレーション}

以上の議論を確認するために数值例による固有値の 計算とシミュレーションを行った．運動方程式は (1)，（3) 式，磁気軸受の制御則は (21)，(22) 式を用 い，以下に示す数値を使用した．乙れは小型の科学衛 星と文献 3)を参考とした.

$$
\begin{aligned}
& I_{x}=I_{z}=200 \mathrm{kgm}^{2} \\
& h=20 \mathrm{Nms} \\
& k_{d}=200 \mathrm{Nm} \\
& k_{c}=-50 \mathrm{Nm}
\end{aligned}
$$

\section{1 固有值の計算}

Fig. 5 は人工衛星の姿勢運動のダンピングファク 夕

$$
\zeta_{s} \equiv-\operatorname{Re}\left(\lambda_{s}\right) / \operatorname{Im}\left(\lambda_{s}\right)
$$

を $k_{r}, \omega_{0}$ をパラメータとして描いたあのである. こ

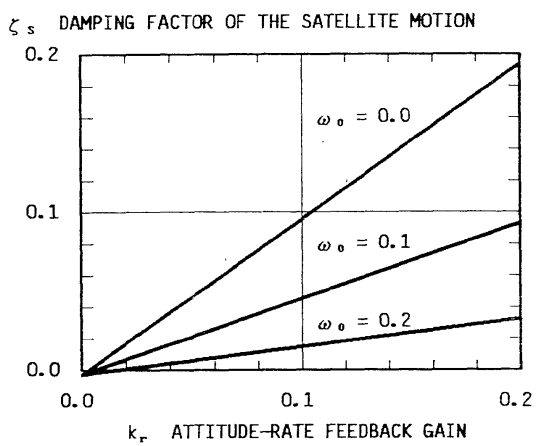

Fig. 5 Damping factor of the satellite motion
れからわかるように， $k_{r}$ を導入するとと により人工衛星の姿勢運動が安定化されて いくことが確認できる． $\omega_{0}$ を大きくする と減衰が劣化するのは， $\omega_{0}$ が低周波数領 域におけるゲインの逆数であるために $k_{r}$ が小さくなったのと等価になるためであ る. $\omega_{0}=0$ の場合は，ほぼ $\zeta_{s}=k_{r}$ であり， (15 a ) 式の結果に一致している。 また， $k_{r}$ $=0$ の場合には $\zeta_{s}$ はわずかに負 (不安定) であるが，乙れはプリセッションを安定化 するために $k_{c}<0$ としたからである.

Fig. 5 のパラメータの範囲ではプリセ ッションの固有值にはほとんど変化がな く, $\lambda_{w} \fallingdotseq-2.4 \pm 10 i$ であった. これは(15 b)式に一致している. (20)式で指定した オブザーバの根む一定值 $\left(\lambda_{0}=-0.40\right)$ であった.

\section{2 シミュレーション}

系の過渡的な応答を見るために数値シミュレーショ ンを行った．Fig. 6 がその結果であり，以下のパラ メータで計算した.

Fig. 6(a ): $k_{r}=0.1, \omega_{0}=0.1$,

Fig. $6(\mathrm{~b}): k_{r}=0.2, \omega_{0}=0.1$,

Fig. 6(c): $k_{r}=0.1, \omega_{0}=0.05$

初期值はいずれの場合む人工衛星の姿勢角速度 $\omega_{x}$ に $0.1 \mathrm{deg} / \mathrm{s}$ を与えた。乙れは姿勢制御のためにスラス タなどを噴射した場合に相当する. 数值積分はルン ゲ・クッタ法を用いた．Fig. 5.から予想されるよう に， $k_{r}$ を大きくするか $\omega_{0}$ を小さくすることによって 人工衛星の姿勢運動の減衰が大きくなり，本方式の効 果の大きいととが確認できる，ただし，Fig. 6(b)， (c)ではさらに大きい $k_{r}$ または小さい $\omega_{0}$ を選んだ が，その結果姿勢運動の減衰は増大するものの，ホイ 一ルのジンバル角度変動の大きくなるととがわかる. これはつぎのように解勫できる。

(21)，(22)式で表わされる制御則の低周波数領域で のゲインは， $s=0$ とすれば,

$$
\begin{aligned}
\frac{U(0)}{\Theta(0)} & =\frac{-K h k_{d} \omega_{0}}{h k_{d} \omega_{0}+k_{r}\left(k_{d}^{2}+k_{c}^{2}\right)} \\
& \fallingdotseq \frac{-K h k_{d} \omega_{0}}{k_{r}\left(k_{d}^{2}+k_{c}^{2}\right)}
\end{aligned}
$$

である. (27) 式は大きい $k_{r}$ や小さい $\omega_{0}$ を用いると， 磁気軸受制御の低周波数領域でのゲインが減少するこ とを示している．したがって，その場合には姿勢変動 などの外乱が加わったりすると大きいジンバル角度変 化が現れてしまうのである，逆に，姿勢変動に敏感に なるために減衰が速やかになったともいえる，従来提 

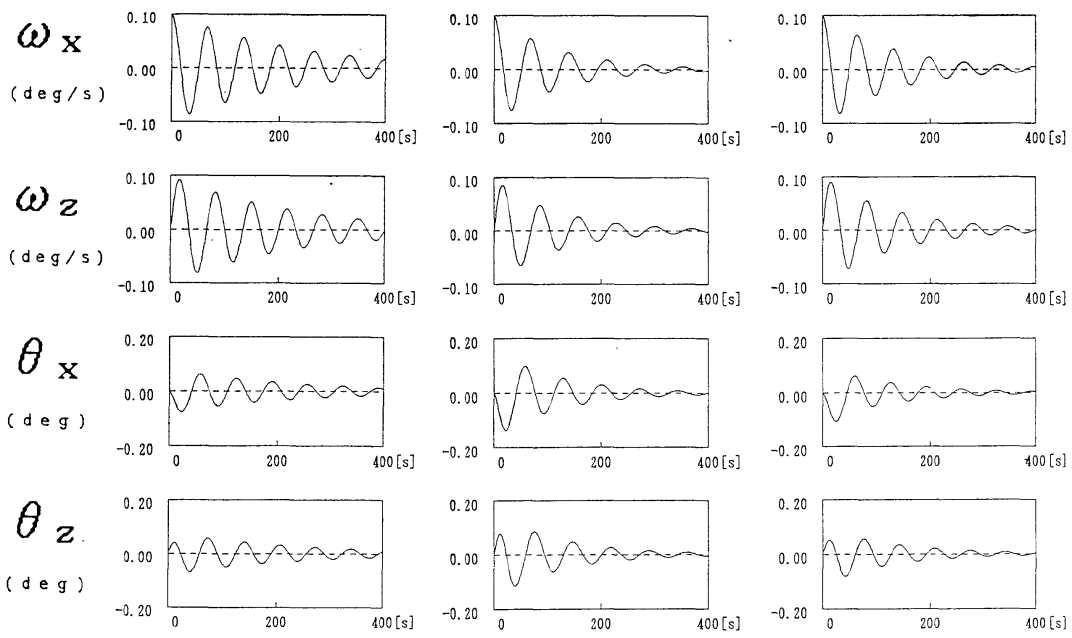

(a) $k_{r}=0.1, \omega_{0}=0.1$

(b) $k_{r}=0.2, \quad \omega_{0}=0.1$

(c) $k_{r}=0.1, \omega_{0}=0.05$

Fig. 6 Simulation results

案されていた正の $k_{c}$ を用いて人工衛星の姿勢を安定 化させる方法は，プリセッションの安定を故意に悪く することによって姿勢運動に敏感になっていたわけで あるが，本方式では(24)式で示したようなさらに低い 周波数のモードを付加することによってその効率を上 げたと考えることもできよう.

しかしながら，低周波数領域でのゲインがあまり小 さいと磁気軸受単独としての制御が困難になる恐れが ある. 結局，オブザーバを用いて人工衛星の姿勢を安 定化できる限界は，磁気軸受に㗢く外乱とそれを許容 できる制御ゲインによって決定されるということにな る.

\section{6. 結論と今後の課題}

磁気軸受ホイールを搭載した人工衛星の姿勢運動を 不安定にしないための磁気軸受制御装置の構成法につ いて検討した．最初に磁気軸受制御のクロスフィード バックが，ホイールと人工衛星の安定に相反する効果 を及隹すととを示し，続いてとの困難を解決するため に姿勢角速度を推定するオブザーバを用いる方式を提 案した. 固有值解析とシミュレーションの結果, 本方 式は従来提案されていた正の $k_{c}$ を用いた磁気軸受制 御に比べると，ホイールの安定を損なうことなく人工 衛星の姿勢運動に大きい減衰を与えることが可能であ るととが確認された。 また，乙のような方法で得られ た磁気軸受の制御回路は，ホイールのジンバル角度を 2 次のローパスフィルタに通してフィードバックする ことと近似的に同等であるととが明らかになった。
ただし，乙れらの解析は近似モデルに基づいている ので，実用化のためにはさらに䛨しい检討が必要であ る. 特に磁気軸受のアクチュエータは非線形性や不平 衡力が大きく，それが姿勢運動へどのような影響を及 ぼすかは完全に明らかにされているわけではない，ま た，本論文では制御装置の伝達関数をできるだけ簡単 な形で導出できるようなオブザーバの根指定を行った が, 磁気軸受制御の低周波数領域でのゲインや外乱抑 制のための条件等を考慮した最適化が望まれる，今後 はこれらの問題を解決するため, 現実のハードゥェア を用いた試験・評価を行う予定である.

本研究に貴重な助言をくださいました九州大学名 誉教授木村春夫様，三菱電機(株) 中央研究所土屋和雄 様, 宇宙科学研究所大島 武様に感謝します.

\section{参 考 文 献}

1）村上 力：人工衛星姿勢制御用磁気軸受フライホイール, 計測と制御，23-1，129/134 (1984)

2) G. Heimbold: Impact of Magnetic Bearing Rotor Design on Satellite Nutational Stability, Journal of Guidance and Control, 7-3, 279/285 (1984)

3）井上: 磁気軸受ホイールの回転試験とジャイロ運動の安 定性，計測自動制御学会論文集，23-3，294/300 (1987)

4) 樋口, 水野: 5 自由度制御型磁気軸受制御系の研究, 計 測自動制御学会論文集，18-5，507/513 (1982)

5) A. Nakajima and C. Murakami: Active Nutation Control of Spacecraft Using a Magnetic Bearing Momentum Wheel with Vernier Gimballing Capability, Technical Report of National Aerospace Laboratory, TR-820 T (1984)

6) T. Lange: Optimal Magnetic Bearing Control for High-Speed Momentum Wheels, Journal of Guid- 
ance and Control, 8-6, 737/742 (1985)

7) M. Inoue, K. Tsuchiya, K. Tanaka, Y. Ohkami and O. Okamoto: An Attitude Control Test Using a Magnetic Double Gimballed Momentum Wheel, Proceedings of the 13th International Symposium on Space Technology and Science, 999/1004 (1982)
8）ワイスバーク，二宮，井上：磁気軸受モーメンタムホイ 一ルを用いた慣性的姿勢決定法, 第 27 回 SICE 学術講 演会予稿集, 719/722 (1988)

9) D. Luenberger: An Introduction to Observers, IEEE Trans. Automatic Control, 16-6, 596/602 (1971) 